Technological Developments in Networking, Education and Automation 

Khaled Elleithy · Tarek Sobh · Magued Iskander •

Vikram Kapila · Mohammad A. Karim •

Ausif Mahmood

Editors

\section{Technological Developments in Networking, Education and Automation}

算 Springer 


\section{Editors}

Prof. Khaled Elleithy

University of Bridgeport

School of Engineering

University Avenue 221

06604 Bridgeport Connecticut

USA

elleithy@bridgeport.edu

Magued Iskander

Polytechnic University

Dept. Civil \& Environmental

Engineering

Jay Street 333

11201 Brooklyn New York

USA

Iskander@poly.edu

Dr. Mohammad A. Karim

Old Dominion University

Monarch Way 4111

23508 Norfolk Virginia

USA

mkarim@odu.edu
Dr. Tarek Sobh

University of Bridgeport

School of Engineering

University Avenue 221

06604 Bridgeport Connecticut

USA

sobh@bridgeport.edu

Dr. Vikram Kapila

Polytechnic University

Dept. Civil \& Environmental

Engineering

Jay Street 333

11201 Brooklyn New York

USA

vkapila@poly.edu

Ausif Mahmood

University of Bridgeport

School of Engineering

University Avenue 221

06604 Bridgeport Connecticut

USA

mahmood@bridgeport.edu

ISBN 978-90-481-9150-5

e-ISBN 978-90-481-9151-2

DOI 10.1007/978-90-481-9151-2

Springer Dordrecht Heidelberg London New York

Library of Congress Control Number: 2010927951

(C) Springer Science+Business Media B.V. 2010

No part of this work may be reproduced, stored in a retrieval system, or transmitted in any form or by any means, electronic, mechanical, photocopying, microfilming, recording or otherwise, without written permission from the Publisher, with the exception of any material supplied specifically for the purpose of being entered and executed on a computer system, for exclusive use by the purchaser of the work.

Printed on acid-free paper

Springer is part of Springer Science+Business Media (www.springer.com) 
To our families

Their continuing support makes all our endeavors possible

$$
\text { And }
$$

To the memory of Professor Natalia Romalis

Her spirit will always be with us 



\section{Preface}

This book includes the proceedings of the 2009 International Conferences on Telecommunications and Networking (TENE 09), Engineering Education, Instructional Technology, Assessment, and E-learning (EIAE 09), and Industrial Electronics, Technology \& Automation (IETA 09). TENE 09, IETA 09 and EIAE 09 are part of the International Joint Conferences on Computer, Information, and Systems Sciences, and Engineering (CISSE 09). The proceedings are a set of rigorously reviewed world-class manuscripts presenting the state of international practice in Industrial Electronics, Automation, Telecommunications, Networking, E-Learning, Instruction Technology, Assessment and Engineering Education.

CISEE 09 was a high-caliber research conference that was conducted online. CISSE 09 received 432 paper submissions and the final program included 220 accepted papers from more than 80 countries, representing the six continents. Each paper received at least two reviews, and authors were required to address review comments prior to presentation and publication.

Conducting CISSE 2009 online presented a number of unique advantages, as follows:

- All communications between the authors, reviewers, and conference organizing committee were done on line, which permitted a short six week period from the paper submission deadline to the beginning of the conference.

- PowerPoint presentations, final paper manuscripts were available to registrants for three weeks prior to the start of the conference

- The conference platform allowed live presentations by several presenters from different locations, with the audio, video and PowerPoint presentations transmitted to attendees throughout the internet, even on dial up connections. Attendees were able to ask both audio and written questions in a chat room format, and presenters could mark up their slides as they deem fit

- The live audio presentations were also recorded and distributed to participants along with the power points presentations and paper manuscripts within the conference DVD.

The conference organizers and we are confident that you will find the papers included in this book interesting and useful.

Khaled Elleithy

Tarek Sobh

Magued Iskander

Vikram Kapila

Mohammad Karim

Ausif Mahmood

Bridgeport, Connecticut

January 2010 



\section{Acknowledgements}

The 2009 International Conferences on Telecommunications and Networking (TENE 09), Engineering Education, Instructional Technology, Assessment, and E-learning (EIAE 09), and Industrial Electronics, Technology \& Automation (IETA 09) and the resulting proceedings could not have been organized without the assistance of a large number of individuals. TENE, EIAE, and IETA are part of the International Joint Conferences on Computer, Information, and Systems Sciences, and Engineering (CISSE). CISSE was founded by Professors Tarek Sobh and Khaled Elleithy in 2005, and they set up mechanisms that put it into action. Andrew Rosca wrote the software that allowed conference management and interaction between the authors and reviewers online. Mr. Tudor Rosca managed the online conference presentation system and was instrumental in ensuring that the event met the highest professional standards. We also want to acknowledge the roles played by Sarosh Patel and Ms. Susan Kristie, our technical and administrative support team.

The technical co-sponsorship provided by the Institute of Electrical and Electronics Engineers (IEEE) and the University of Bridgeport is gratefully appreciated. We would like to express our thanks to Prof. Toshio Fukuda, Chair of the International Advisory Committee and the members of the TENE, EIAE and IETA Technical Program Committees.

The excellent contributions of the authors made these world-class conference proceedings possible. Each paper received two to four reviews. The reviewers worked tirelessly under a tight schedule and their important work is gratefully appreciated. A complete list of reviewers is provided in the book.

Khaled Elleithy

Tarek Sobh

Magued Iskander

Vikram Kapila

Mohammad Karim

Ausif Mahmood

Bridgeport, Connecticut

January 2010 



\section{Contents}

Reviewers List xix

1. Education in the Clouds: How Colleges and Universities are Leveraging Cloud Computing..... .1 David C. Wyld and Rusty L. Juban

2. Weak Orderings of Knowledge States.

Sylvia Encheva and Sharil Tumin

3. Problem Based Learning: Obtaining Enzyme Kinetics Parameters Integrating Linear Algebra, Computer Programming and Biochemistry Curriculum

A. Regalado-Méndez et al.

4. Adaptive Assessments using Open Standards Héctor G. Barbosa León et al.

5. Online Academic Advising Support

Fawzi Albalooshi and Safwan Shatnawi

6. Using Computer Game to Share knowledge.

Mazeyanti M Ariffin et al.

7. Following the Paper Trail: Measuring the Economic and Environmental Impact of Digital

Content Delivery

Vanessa K. Cox et al.

8. Context Driven Personalized e-Learning Environment Provided as a State Service

Deniss Kumlander

9. Exploring Teachers’ Beliefs about Digital Citizenship and Responsibility

Harrison Hao Yang and Pinde Chen

10. Faculty Driven Assessment of Critical Thinking: National Dissemination of the CAT Instrument.....55 Barry Stein et al.

11. Enhancing the Instruction of Introductory Electric Circuit Courses using MATLAB

Thomas Yang et al.

12. Istopolis: Design Issues and Evaluation' Results of an Integrated Web-Based

Educational Application

C. T. Panagiotakopoulos et al. 
13. TEAC ${ }^{2} \mathrm{H}-\mathrm{RI}$ : Educational Robotic Platform for Improving Teaching-Learning Processes of Technology in Developing Countries.

Juan J. González et al.

14. Selecting Patterns for the Evaluation of Systems

Dmitry Zub and Erki Eessaar

15. Effectiveness of Collaborative Learning in Teaching Information Systems

Ioana Tuugalei Chan Mow

16. Implementation of a Curriculum Management System at a Faculty of Medicine - Lessons

Learned from a Pilot Project.

Aarti Paul et al.

17. Use of Ontology for Reusing Web Repositories for eLearning

Punam Bedi et al.

18. Actual and Future Trends of the E-education and Its Costs Specification in the Czech Republic

M. Hedvicakova and P. Maresova

19. Modern Improvements in the Digital Logic Laboratory

K. M. Noga and M. Radwanski

20. e-Cheating and Calculator-Technology

Zeenath Reza Khan

21. Perspectives on Critical Thinking through Online Discussion Forums in Engineering

Mathematics

S. M. Jacob and H. K. Sam

22. Digital System Description Knowledge Assessment

K. Jelemenská et al.

23. Wikibooks as Tools for Promoting Constructivist Learning in Higher Education: Findings

from a Case Study

Ilias Karasavvidis

24. The Impact of the Context of an Information System on Strategic Information

Quality - The Institute of Technology Sector in Ireland

Laurence P. Elwood and Owen V. Foley

25. Can Mobile Computing Help Reverse the Decline in Informatics Studies?

D.Vitkute-Adzgauskiene and V.V. Fomin

26. Towards an Academic Social Network for Bologna Process

João C. Ferreira and Porfírio P. Filipe

27. Supporting Knowledge Discovery in an eLearning Environment Having Social Components 157 Paola Monachesi et al. 
28. Computer Numerical Control, Mass Customization and Architectural Education in an Emergent Economy

Neander F. Silva et al.

29. Application of Project Based Study in the Learning Process: A Case Study

Ashfaque A Chowdhury et al.

30. Interdisciplinary Automation and Control in a Programmable Logic Controller (PLC)

Laboratory

Jack Toporovsky et al.

31. Stereo Spectral Imaging System for Plant Health Characterization

S. C. Yoon and C. N. Thai

32. Transition Network for Automation Modeling: A Case Study.....

Yuval Cohen et al.

33. Computational Modeling and Simulation of a New Energy-Saving Sealing Unit

in Industrial Applications

Zheng (Jeremy) $\mathrm{Li}$

34. Design of An Intelligent Solar Tracking System Using PIC18F452 Micro Controller

Mostefa Ghassoul

35. Adaptive Two Layers Neural Network Frequency Controller for Isolated Thermal

Power System

Ognjen Kuljaca et al.

36. Optimal Controller Comparison Using Pareto Fronts

David Moore

37. Interaction with Objects in Virtual Environments

Jesús A. Verduzco-Ramírez et al.

38. One Approach for Training of Recurrent Neural Network Model of IIR Digital Filter

Stefanova S.A.

39. Classification of the Power Transformers using Dissolved Gas Analysis

T. C. B. N. Assunção et al.

40. Modelling Control of Pore Number and Radii Distribution in Single-Cell Electroporation

Sadhana Talele and Paul Gaynor

41. Single Allocation P-Hub Median Problem to Monitor Land Borders by Using

Unmanned Aircraft

Yasemin Akkuş and İnci Sarıçiçek 
42. LPT to RS232 communication converter 243

Grofu Florin and Cercel Constantin

43. Simulation model of Coremaking Plant

Stefan Belev and Miroslav Penchev

44. Depth Calculation using Computer Vision and Sift

Edson CAVALCANTI Neto et al.

45. Dynamic of New Technologies in Switching Power Devices IGBTs

Christian Ayala Esquivel et al.

46. Anisotropic Percolating Pathways in the Thin Films of Polymeric PEDT/PSS Complex

and their Relation to the Electrical Conductivity as Revealed by the Mesoscale Simulation.

Toomas Kaevand et al.

47. Predicting Trading Signals of Sri Lankan Stock Market Using Genetic Algorithms

and Neural Networks

M. M. K. Dassanayake and Chandima Tilakarathne

48. An Automatic Measurement Algorithm for the Diameters of Carbon Nanotubes by

Using Image Processing

Yoichiro Iwasaki et al.

49. Object Detection in Foveated Images

Abulfazl Yavari and H.R. Pourreza

50. Digital Semi-Controlled Rectifier using a Microcontroller

Emmanuel E. Rached et al.

51. Generalized Minimum Variance Controller with Dynamic Pole Assignment to Improve

Performance in Industrial Applications

M.A. Paz Ramos et al.

52. Automated Detection of Sunspots and Sunspot Groups in Full-Disk Solar Images

Sarab F. Majed et al.

53. Stochastic Model Based Approach for Biometric Identification

Mofakharul Islam et al.

54. A New Stochastic Model Based Approach for Object Identification and Segmentation in Textured Color Image.

Mofakharul Islam and Paul A. Watters

55. An Unsupervised Stochastic Model for Detection and Identification of Objects in Textured Color Images Using Segmentation Technique

Mofakharul Islam and Paul A. Watters 
56. Automated Classification of Sunspot Groups with Support Vector Machines 321

Mehmmood A. Abd et al.

57. A Novel Ballistics Imaging System for Firearm Identification

Dongguang $\mathrm{Li}$

58. Color Seal Segmentation and Identification

Dongguang $\mathrm{Li}$

59. Efficient SOPC-based Multicore System Design using NOC

Vignesh Veerapandian and Xingguo Xiong

60. Architecture and Initial Performance Indicators of New OPCUA Automation Protocol

Stack Java Implementation......

Mikko Salmenperä and Mikko Salonen

61. Automatic Segmentation of Cardiac Cavity Images Using Collinear and Triangle Equation

Riyanto Sigit et al.

62. Both Side More-Output Transmission with Harmonic Gear.

Jozef Hal'ko

63. Intelligent Plasma Monitoring Systems Based on Optical Methods and Chromatic Modulation........361

Dimitrios Tomtsis

64. A Neoteric Chaotic \& Adaptive Watermarking Scheme for Colored Images

Navita Srivastava and Achintya Singhal

65. Rotary Transducer

Ilie Borcosi et al.

66. Regression Analysis about Humidity Elimination from Diesel Fuel Via Bioorganic

Compounds to Increase Antifouling Action

C. G. Tsanaktsidis et al.

67. Optimal Threshold for Locating Targets Within a Surveillance Region Using a Binary

Sensor Network

Zhenxing Luo and Thomas C. Jannett

68. A Proposal of a Nonlinear Observer Applied to the Heat Exchange Phenomena in a

Double Pipe Heat Exchanger

J. F. Briones et al.

69. Vibration Signal Processing by Deconvolution Method

Popescu Ion Marian and Runceanu Adrian

70. An IT Change Management Tool to Optimize Scheduling and Planning 399

Denílson Cursino Oliveira and Raimir Holanda Filho 
71. A Low-Power Content-Addressable Memory (CAM) using Pipelined Search Scheme 405 Yibo Song et al.

72. Design and Optimization of Piezoelectric Dual-Mode Micro-Mirror 411 Jichao Zhong et al.

73. Device for Measurement of Clamped Joints Friction Torque 417 Eva Batešková et al.

74. Self-Optimization for Dynamic Scheduling in Manufacturing Systems 421 Ana Madureira and Ivo Pereira

75. A Decomposition Method in Modeling Queuing Systems

Eimutis Valakevicius et al.

76. Modular Design and Structure for a Mobile Sensory Platform Ayssam Elkady et al.

77. wradvs: A Didactic Server for IPv6 Stateless Autoconfiguration Gabriel Abadi et al.

78. Securing P2P Wireless Communications by Deploying Honeytokens in a Cooperative Maritime Network

Jonathan White et al.

79. Integrating Information Security into Quality Management Systems Margareth Stoll

80. Evaluation of Asynchronous Event Mechanisms for Browser-based Real-time Communication Integration

Keith Griffin and Colin Flanagan

81. An Ontology-based Intrusion Detection for RFID Systems M. Esposito and G. Della Vecchia

82. A New Algorithm and its Implementations for RC Filters Guoliang Zeng

83. A Computationally Dynamic Resource Management for Multicarrier Communications in Downlink for OFDMA Systems

Kabaou Mohamed Ouwais et al.

84. A General Method for Synthesis of Families of Orthogonal Complementary Codes

B. Y. Bedzhev and M. P. Iliev

85. E-Speed Start- A Window Based Additive Increase, Multiplicative Decrease Network Congestion Control Technique.

I. K. Oyeyinka et al. 
86. Common-Wavelengths Design Scheme for Efficient Management of Spare Resources in WDM Networks

Ardian Greca

87. ICMP Covert Channel Resiliency

Kristian Stokes et al.

88. Chip-to-chip Free-space Optical Interconnection Using Liquid-crystal-over-silicon Spatial

light modulator

Sadia Sultana et al.

89. GA based Neural Network Retraining using Adaptive Genetic Operations

C. I. Bauer et al.

90. Decision Support for IP Uplink and Routing Choice

Peng Su and Zhengping Wu

91. Differential Cryptanalysis of Blow-CAST-Fish

Xiaoling Sun and Meiqin Wang

92. A Keyless Polyalphabetic Cipher

William J. Spezeski

93. Vertical Handover between WiFi Network and WiMAX Network According to IEEE 802.21

Standard

Mariem Thaalbi and Nabil Tabbane

94. Study on the Impact of Node Density and Sink Location in WSN

Plamen Z. Zahariev et al.

95. An Algorithm for Synthesis of Families of Generalized Orthogonal Complementary Pairs

B. Y. Bedzhev and M. P. Iliev

96. Low Message Overhead Clustering Algorithm for Wireless Sensor Networks.

Batista et al.

97. On the Design of SOHO Networks

Lawan Ahmed Mohammed

98. Study of UMTS Handover Scenarios

B. Issac

99. Reduction of Energy Consumption in WSN using an Approach Geocast.

Harilton da S. Araújo et al.

100. Conflicts in Online Social Network Privacy Policy

Zhengping Wu and Yuanyao Liu 
101. Developing a Feedback Model for Managing Congestion in Packet Switched Wide Area Networks 579

E. F. Ogbimi et al.

102. Voice Gateway to IP-PSTN Integration and NGN Architecture 585 Geneflides Laureno da Silva and Raimir Holanda Filho

103. An Algorithm for Route Selection on Multi-sink Wireless Sensor Network Using Fuzzy Logic .......591 Líliam Barroso Leal et al.

104. Mining Mobile Sequential Patterns in Wireless Cellular Networks Joshua G. Bradley and Sherif S. Rashad

105. Agile Software Development Methods and its Advantages 603 Soly Mathew Biju

106. Toward a High Performance Grid Site RO-14-ITIM and the Contribution to WLCG F. Farcas and G. Popeneciu

107. A MFI4OR-based Approach of Semantic Annotation for Web Service. 615 Cheng Zeng et al.

108. Ethernet Node for Serial Communications A. S. Popa et al.

109. EvalTool for Evaluate the Partitioning Scheme of Distributed Databases Adrian Runceanu and Marian Popescu

110. Automatic Creation of Daily News Digests from Internet News Sites David B. Bracewell

Index 


\section{Reviewers List}

\begin{tabular}{|c|c|c|c|c|c|}
\hline Abbas & Riazi & Hiten & Choudhury & Peng & $\mathrm{Su}$ \\
\hline Ahmad Sofian & Shminan & Ilias & Karasavvidis & Pinde & Chen \\
\hline Alejandro & Regalado & Ilie & Borcosi & Popescu & Marian \\
\hline Alen & Hajnal & Inci & Saricicek & Razib Hayat & Khan \\
\hline Andrew & Dimmond & Indrajit & Mandal & Reza & Vahidnia \\
\hline Anu & Gupta & Ioana & Chan Mow & Riyanto & Sigit \\
\hline Ardian & Greca & Jan & Genci & Sadhana & Talele \\
\hline Ausif & Mahmood & Joao & Ferreira & Sadia & Sultana \\
\hline Barry & Stein & Jozef & Halko & Sat & Sharma \\
\hline Biju & Issac & Jozef & Mašcenik & Seibu & Mary Jacob \\
\hline Bingyang & Zhou & Kabaou & Mohamed Ouwais & Shafqat & Hameed \\
\hline Bo & Yuan & Katarina & Jelemenska & Shen & Chao \\
\hline Bojan & Medjo & Keith & Griffin & Smita & Shukla \\
\hline Chi & Thai & Krystyna Maria & Noga & Sridhar & Chandran \\
\hline Chris & Panagiotakopoulos & Liciniu-Alexandru & Kovacs & Stefan & Belev \\
\hline Christian & Ayala Esquivel & Lucia A. & Fernandes & Sylvia & Encheva \\
\hline David & Moore & Luy & Nguyen Tan & Teodor & Iliev \\
\hline David & Wyld & Maduranga & Dassanayake & Teresa Cristina & Bessa Assunção \\
\hline Denilson & Oliveira & Magued & Iskander & Thomas & Yang \\
\hline Deniss & Kumlander & Margareth & Stoll & Vanessa & Cox \\
\hline Dimitrios & Tomtsis & Martina & Hedvicakova & Vini & Kanvar \\
\hline Dmitry & $\mathrm{Zub}$ & Massimo & Esposito & Xingguo & Xiong \\
\hline Edson & Cavalcanti Neto & Mazeyanti & M Ariffin & Yenumula & Reddy \\
\hline Enrique & Araiza Montes de Oca & Michel & Owayjan & Yoichiro & Iwasaki \\
\hline Eric & Gamess & Mikhail & Stetsenko & Yuanyao & Liu \\
\hline Ernest & Hibbs & Mofakharul & Islam & Yuval & Cohen \\
\hline Fawzi & Albalooshi & Mohammad & Karim & Zheng (Jeremy) & $\mathrm{Li}$ \\
\hline Grofu & Florin & Mohammad & Muqri & Zhenxing & Luo \\
\hline Harrison & Yang & Monika & Verma & & \\
\hline Hector & Barbosa Leon & Ognjen & Kuljaca & & \\
\hline
\end{tabular}

